\title{
Assessing the Awareness and Readiness of the Malaysian Furniture Industry for Industry 4.0
}

\author{
Jegatheswaran Ratnasingam, ${ }^{\mathrm{a}, *}$ Lee Y. Yi, ${ }^{\mathrm{a}}$ Amir A. A. Azim, ${ }^{\mathrm{a}}$ Rasmina Halis, ${ }^{\mathrm{a}}$ Lim \\ Choon Liat, ${ }^{\mathrm{b}}$ Albert Khoo, ${ }^{\mathrm{b}}$ Muhamad M. M. Daud, ${ }^{\mathrm{a}}$ Abdul L. Senin, ${ }^{\mathrm{a}}$ Hazirah A. Latib, \\ Maria V. Bueno, ${ }^{\mathrm{c}}$ Marcin Zbiec, ${ }^{\mathrm{d}}$ Josefina Garrido, ${ }^{\mathrm{e}}$ Juanjo Ortega, ${ }^{\mathrm{e}}$ María V. Gómez, ${ }^{\mathrm{f}}$ \\ Rokiah Hashim, ${ }^{\mathrm{g}}$ Sarani Zakaria, ${ }^{\mathrm{h}}$ Shahriman Z. Abidin, ${ }^{\mathrm{i}}$ and Mohd Nor Z. M. Amin ${ }^{\mathrm{j}}$
}

\begin{abstract}
The lack of knowledgeable and skilled workers is a major challenge faced by the Malaysian furniture sector. It hinders industrial productivity and its ability to move up the value-chain by adopting high technology. Therefore, in order to assess the awareness and readiness of the Malaysian furniture industry for Industry 4.0, a questionnaire-based survey was conducted with a sample of 778 large-, medium-, and small-sized furniture manufacturers throughout Malaysia. This study is part of an on-going Erasmus+ program funded by the European Commission, initiated in 2018 to develop a university-level education program to train workers capable of handling Industry 4.0 technologies for the furniture and wood industry in Malaysia. The results revealed that manufacturers of wood-based panel and metal furniture were more prepared to adopt automation and Industry 4.0 technologies compared to solid-wood and leather furniture manufacturers. The benefits from Industry 4.0 technologies include increased production capacity, product diversity, cost competitiveness, and workforce reduction. Further, the results of this study suggest that the lack of knowledgeable and skilled workers to handle Industry 4.0 technology is a concern among furniture manufacturers, and possibly the proposed university-level Industry 4.0 program may be beneficial to train workers for the future of the industry.
\end{abstract}

Keywords: Automation; Furniture; Industry 4.0; Cost benefit; Productivity

Contact information: a: Universiti Putra Malaysia, Faculty of Forestry, 43400 UPM, Serdang, Selangor, Malaysia; b: Malaysian Furniture Council, Lot 19A, $19^{\text {th }}$ Floor, Menara PGRM, 8, Jalan Pudu Ulu, Cheras, 56100 Kuala Lumpur, Malaysia; c: Universidad Politecnica De Cartagena, C.P 30202 Cartagena, Spain; d: Warsaw University of Life Sciences-WULS, Nowoursynowska 166 St., 02-787 Warsaw, Poland; e: Technological Centre of Furniture and Wood of the Region of Murcia (CETEM), Perales S/N, 30510 Yecla (Murcia), Spain; f: Karlsruhe Institute of Technology, P.O. Box 3640, 76021 Karlsruhe, Germany; g: Universiti Sains Malaysia, 11800 USM Penang, Malaysia; $h$ : Universiti Kebangsaan Malaysia, 43600 UKM Bangi, Selangor, Malaysia; i: Universiti Teknologi MARA Malaysia (UiTM), 40450 Shah Alam, Selangor, Malaysia; j: Malaysian Timber Industry Board (MTIB), Menara PGRM, 8, Jalan Pudu Ulu, 55300 Kuala Lumpur, Malaysia; *Corresponding author: jswaran1965@ gmail.com

\section{INTRODUCTION}

The wood and wood-based sector in Malaysia has grown from humble beginnings in the early 1980s to become an important multi-billion-dollar export-oriented sector within three decades. In fact, Malaysia has been a leading exporter of tropical saw-logs, sawn timber, and plywood since colonial times. The government, in its efforts to improve down-

Ratnasingam et al. (2020). "Industry 4.0, Malaysia" BioResources 15(3), 4866-4885. 4866 
stream processing and value-adding activities, imposed a ban on saw-log exports from Peninsular Malaysia in 1978, which was followed by a series of export quotas and export tax on sawn-timber. Such policy moves were able to restrict the exporting of primary wood commodities but were insufficient to encourage a large-scale transformation of the woodbased sector to down-stream processing. To encourage down-stream wood processing, the government implemented a series of Industrial Master Plans (IMP). The first IMP (1986 to 1995) focused on down-stream processing, the second IMP (1996 to 2005) emphasized greater value-added manufacturing, especially in the furniture and builders' carpentry \& joinery (BCJ) sectors, and the third IMP (2005 to 2020) prioritized original design and creativity. The transformation of the Malaysian wood-based sector brought about by these IMPs was profound, as export revenues from wood-based products surged from RM 914 million in 1980 to RM 22.3 billion in 2018 (MTIB 2019). From an industrial perspective, the successful transformation of the Malaysian wood-based sector into a large value-added export-oriented sector became the envy of many nations, and the Malaysian model has been extensively studied and replicated elsewhere to spur industrial growth (Ratnasingam et al. 2018).

\section{The Malaysian Furniture Industry}

A testament to the success of the Malaysian wood-based industry is the booming furniture sub-sector. In recent decades, the furniture sub-sector has emerged as the star performer within the overall Malaysian wood-based industry, commanding almost $40 \%$ of the industry's total export earnings. In 2018, furniture exports were valued at RM 9.83 billion, despite the highly competitive global market. As a large export-oriented furniture manufacturer, Malaysia exports $85 \%$ of its annual furniture production volume to more than 160 countries throughout the world, with the USA, Japan, Australia, Singapore, Europe, India, United Arab Emirates, and South Africa being the main markets (MTIB 2019). With this sterling performance, it is no surprise that the furniture industry is on track to achieve its target of RM 12 billion in export receipts by 2020.

Nevertheless, the rapid expansion of the Malaysian furniture industry during the 20-year period between 1986 and 2005 coincided with the implementation of the $1^{\text {st }}$ and $2^{\text {nd }}$ Industrial Master Plans. However, since 2006, the pace of annual growth has reduced significantly, because the industry has been plagued with stagnating productivity growth and hence, reduced competitiveness amidst the Asian furniture powerhouses, such as China and Vietnam. The growth of the Malaysian furniture industry in the early years was fueled primarily by the availability of input factors, especially raw materials and labor at competitive rates. The growth driven by these incremental capital inputs could not be sustained when the other lower-cost furniture manufacturing nations joined the furniture manufacturing arena, which eliminated the comparative advantages from factor inputs. In fact, China and Vietnam have emerged as the two most important furniture exporters in the world, displacing Malaysia to the tenth position in the league of the 10 most important furniture exporters in the world in 2018 (CSIL 2019).

Generally, the Malaysian furniture sector can be categorized into four main types by the material predominantly used (wooden, panel-based, soft/leather, and metal). However, wooden furniture accounts for the largest proportion of furniture produced, making up almost $83 \%$ of the total volume of furniture produced (Ratnasingam 2015).

Ratnasingam et al. (2020). "Industry 4.0, Malaysia" BioResources 15(3), 4866-4885. 4867 
It has been highlighted that the two most important challenges faced by the Malaysian furniture industry are the unsustainable raw materials supply and the laborintensive industry that is highly dependent on foreign contract workers, who make up almost $67 \%$ of the total industry workforce. To alleviate the uncertainty in raw materials supply, importation of materials, establishment of plantation forests, and increased efforts to improve recovery in material processing are being widely practiced throughout the country, and these measures have already bearing success (Ratnasingam 2015).

However, the problem associated with the labor-intensive nature of the furniture industry remains a huge challenge to productivity. The over-dependence on foreign contract workers created a low-wage economy that is unattractive to the local workforce. Further, the furniture manufacturing industry is associated with the " $3 \mathrm{D}$ " (dirty, dangerous, and difficult) syndrome, making it less desirable to local workers. The prevailing low-wage economy serves as a strong disincentive to manufacturers' wanting to invest in technology and automation, as the low-cost workforce offsets the much-publicized benefits of adopting technology and automation. The lack of technology and automation also hamper the efforts to move up the value-chain and boost creativity, which explains the stagnating valueaddition and productivity growth of the Malaysian furniture industry (Ratnasingam 2015).

\section{State of Automation Application in the Malaysian Furniture Industry}

Previous research by $\mathrm{Ng}$ (2011) has shown that automation may offer a long-term solution to reduce labor cost, especially in the labor-intensive furniture industry. The report also suggests that the adoption of automated technologies may be able to reverse the trend of stagnating labor productivity and increase value-addition in the Malaysian furniture industry. A similar observation was reported by the Academy of Sciences Malaysia (ASM) in 2015, which noted that most furniture factories prefer low-cost automation solutions and stand-alone workstations, such as computer-numerical-control (CNC) workstations, capable of performing repetitive tasks for higher production volumes. In fact, there appears to be a reluctance among manufacturers to venture into automated technologies, despite the financial incentives offered by the Malaysian Industrial Development Authority (MIDA) and the Malaysian Timber Council (MTC) for the adoption of automated technologies.

It has been found that automation in manufacturing sectors can be categorized into three major groups: (i) low-range automation or low-cost automation (LCA), (ii) mid-range automation technologies, which still requires the skilled supervision to ensure conformity, and (iii) high-range automation technologies, which operate through a machine-human interphase without any direct supervision. In this context, almost $48 \%$ of all automation technologies currently used in the furniture industry in Malaysia fall under category 1, while category 2 and category 3 account for 33\% and 19\%, respectively (Ratnasingam 2015). This is likely due to the prevailing lack of information and communication technologies (ICT) applied in the furniture industry, and the lack of the knowledgeable and skilled workers necessary to adopt and maintain such technologies.

However, this lack of ICT application and skilled workers who are ICT savvy are also lacking in other resources-based industries in the country. To overcome the overreliance on contract foreign workers who currently make up approximately $34 \%$ of the country's total workforce, the government formulated the National Policy on Industry 4.0

Ratnasingam et al. (2020). "Industry 4.0, Malaysia" BioResources 15(3), 4866-4885. 4868 
in 2018. This policy was spearheaded by the Ministry of International Trade and Industry (MITI). With this policy, the government aimed to help transform the manufacturing sector into a high technology, high value-added, and globally competitive sector. Although the initial focus was on sectors, such as automotive, consumer electronics, and rubber product manufacturing, the furniture and wood-industry was also identified as a potential sector for Industry 4.0 adoption. Owing to the prevailing organizational culture and the predominance of small and medium enterprises (SMEs) in the furniture sector, the issue of readiness and awareness of Industry 4.0 is also ambiguous, and warrants a study.

Nevertheless, one of the prerequisites for the successful implementation of Industry 4.0 is the ready availability of skilled and knowledgeable workers who are trained by a rigorous education program on the relevant enabling technologies (Bauer et al. 2016; Müller and Voigt 2017). In the furniture and wood-based industries, this problem is even more acute due to the high reliance on foreign contract workers, who in many instances have little or no formal education. It is hoped that local institutions of higher learning will developed relevant programs to train local workers with such knowledge and skills, which inevitably will entice them to seek a career in the furniture industry, which also offers a higher wage due to their special qualification and skills. In this context, the Erasmus+ MAKING 4.0 program for the furniture and wood industry in Malaysia initiated in 2018 and funded solely by the European Commission, has the objective of developing an Industry 4.0 education curriculum for Malaysian universities in collaboration with partner universities from Europe.

\section{Industry 4.0: Its' Development, Enabling Technologies and Barriers to Adoption}

The end of the $18^{\text {th }}$ century was indeed the start of the industrial revolution when mechanical production facilities powered by water and steam were first used. In the $20^{\text {th }}$ century, the second industrial revolution unfolded, when the concept of mass production emerged with the discovery of electricity as well as the division of labor. Automation, industrial electronics, and information technology brought about the $3^{\text {rd }}$ Industrial revolution which started circa 1970s (Ghobakhloo 2018). The $4^{\text {th }}$ industrial revolution was driven by the horizontal expansion of information technology, in which interconnectedness is a fundamental requirement (Lee et al. 2018).

Inevitably, new avenues of production are emerging through communicating objects, learning machines, and autonomous robots (Valenduc and Vendramin 2016). The term "Industry 4.0" describes the increasing digitization of the entire supply chain, which makes it possible to connect actors, objects, and systems based on real-time data exchange (Dorst et al. 2015). This interconnection enables products, machines, and processes with artificial intelligence to adapt and change according to real-time situations (Hecklau et al. 2016). According to Roblek et al. (2016) the five key elements of Industry 4.0 are: (1) digitization, optimization and customization of production; (2) automation and adaptation; (3) human-machine interaction; (4) value-added services and stores, and (5) automatic data exchange and communication. These elements are mutually interconnected, and they lead to the unique characteristics on Industry 4.0, which are, cyber-physical systems, internet of things (IoT), internet of services (IoS), and smart factories (Hermann et al. 2015). The application of connected and embedded systems with software solutions makes it possible

Ratnasingam et al. (2020). "Industry 4.0, Malaysia" BioResources 15(3), 4866-4885. 4869 
to control and monitor production through the processing and analysis of information extracted from the production process. Overall, Industry 4.0 technologies support decisionmaking and therefore contribute significantly to increasing productivity (Zhong et al. 2017).

Industry 4.0, also referred to as smart manufacturing, which marries physical production and operations with smart digital technology, machine learning, and big data, creates a more holistic and better connected ecosystem for manufacturing companies as well as supply chain management (Arnold et al. 2016). Although manufacturing companies may differ from each other, a common problem faced is the need for real-time insights across the whole manufacturing chain. This is the essence of Industry 4.0, which should improve manufacturing efficiency and revolutionize the way the entire businesses grow and operate. Therefore, Industry 4.0 will have an impact on the future of the furniture manufacturing industry, and it is important to assess the readiness of the industry for such transformational technologies.

In the furniture industry, the application of Industry 4.0 encompasses five components, i.e., the digital component, intelligent machine, horizontal networking, vertical networking, and the smart work-piece (Anderl et al. 2018). It is widely accepted that Industry 4.0 takes the emphasis on digital technology to a whole new level, by improving interconnectivity through the internet of things (IoT), access to real-time data, and the introduction of cyber-physical systems. This allow business owners to better control and understand every aspect of their operation, and it allows them to leverage instant data to boost productivity, improve processes, and drive growth (Arnold et al. 2016). The rapidly evolving and converging technologies of Industry 4.0 is pushing the boundaries of new product development through additive manufacturing and advanced materials. With big data analytics, rich simulations, and augmented reality supported by cyber-security functions, the lines between physical and digital realms are blurred, allowing furniture designs to be taken to greater heights. The human capacity is also enhanced through artificial intelligence and autonomous robots in the smart factory environment. Many of these technologies have been available for several years, but the interaction and resulting convergence of these technologies is creating an unprecedented pace and breadth of impact on the global manufacturing industries. Consequently, the impact of such technologies on the furniture sector will likely be sizable. Table 1 provides a summary of the key enabling technologies of Industry 4.0.

Despite the much touted benefits of applying automation and Industry 4.0 technologies in the manufacturing sector, there are barriers to its adoption and effective utilization. Müller and Voigt (2017) reported that one of the major barriers to the implementation of Industry 4.0 is the lack of skilled workforce, along with the requirement to retrain staff to fit the new manufacturing circumstances. The same report together with the study by Erol et al. (2016) also identified the shortage of financial resources the low degree of product standardization as the other barriers faced to the implementation of Industry 4.0. Paritala et al. (2017) noted that standardization problems may occur in interorganizational relationships, as well as in tools and systems inside manufacturing companies.

Ratnasingam et al. (2020). "Industry 4.0, Malaysia" BioResources 15(3), 4866-4885. 4870 
Table 1. Key Enabling Technologies of Industry 4.0

\begin{tabular}{|c|c|c|c|}
\hline \multicolumn{2}{|c|}{ Enabling Technologies } & Definition & Opportunities \\
\hline 1 & $\begin{array}{l}\text { Advanced } \\
\text { Manufacturing } \\
\text { Solutions }\end{array}$ & $\begin{array}{c}\text { This involves } \\
\text { interconnected and modular } \\
\text { systems for automated } \\
\text { industrial plans. Automatic } \\
\text { material-moving systems, } \\
\text { advanced robotics, and low } \\
\text { cost automation are } \\
\text { examples of such } \\
\text { technology. }\end{array}$ & $\begin{array}{l}\text { - Reduces set-up costs, errors, and } \\
\text { machine downtimes. } \\
\text { - Flexibility in production through } \\
\text { workers' participation. } \\
\text { - Higher production capacity. }\end{array}$ \\
\hline 2 & $\begin{array}{l}\text { Augmented } \\
\text { Reality }\end{array}$ & $\begin{array}{l}\text { This involves the use of } \\
\text { mobile devices that enrich } \\
\text { human sensory perception } \\
\text { (i.e. sound, smell and } \\
\text { touch) through the access } \\
\text { to virtual environments. }\end{array}$ & $\begin{array}{l}\text { - Higher speed in prototyping with } \\
\text { augmented virtual reality. } \\
\text {-Superior product quality and less } \\
\text { production waste. }\end{array}$ \\
\hline 3 & Internet of Things & $\begin{array}{l}\text { This corresponds to a set of } \\
\text { devices and intelligent } \\
\text { sensors that facilitate } \\
\text { communication between } \\
\text { people, products, and } \\
\text { machines. }\end{array}$ & $\begin{array}{c}\text { - Higher product evaluations based } \\
\text { on customers' wants. } \\
\text {-A greater guarantee of products' } \\
\text { origin, use, and destination, which } \\
\text { ensures traceability. } \\
\text {-Greater interconnection along the } \\
\text { supply and distribution chains which } \\
\text { allows proactive maintenance. }\end{array}$ \\
\hline 4 & $\begin{array}{l}\text { Big Data } \\
\text { Analytics }\end{array}$ & $\begin{array}{c}\text { This relates to the } \\
\text { technologies that capture, } \\
\text { archive, analyze, and } \\
\text { disseminate large quantities } \\
\text { of data from products, } \\
\text { processes, machines, and } \\
\text { people. }\end{array}$ & $\begin{array}{l}\text { - Higher product evaluations from the } \\
\text { customer due to faster } \\
\text { communications. } \\
\text { - Flexibility due to the ability to } \\
\text { estimate demand; } \\
\text { - Optimized the supply chain. }\end{array}$ \\
\hline 5 & Cloud Computing & $\begin{array}{l}\text { Cloud computing } \\
\text { technologies for archiving } \\
\text { and processing large } \\
\text { quantities of data with high } \\
\text { speed, flexibility, and } \\
\text { efficiency. }\end{array}$ & $\begin{array}{l}\text { The opportunities and risks from } \\
\text { using these technologies can be } \\
\text { added to those involved in Big } \\
\text { Data Analytics and Internet of } \\
\text { Things. }\end{array}$ \\
\hline 6 & Cyber Security & $\begin{array}{l}\text { This includes security } \\
\text { measures designed to } \\
\text { protect the flow of } \\
\text { information over } \\
\text { interconnected corporate } \\
\text { systems. }\end{array}$ & $\begin{array}{l}\text {-These technologies are designed } \\
\text { to support others by limiting the } \\
\text { risks linked to the use of such } \\
\text { technologies. }\end{array}$ \\
\hline 7 & $\begin{array}{c}\text { Additive } \\
\text { Manufacturing }\end{array}$ & $\begin{array}{l}\text { This additive production } \\
\text { process allows for complex } \\
\text { products by creating layers } \\
\text { of materials. A notable } \\
\text { example is 3-D printing. }\end{array}$ & $\begin{array}{l}\text {-Higher speed in prototyping. } \\
\text {-Superior product quality and less } \\
\text { production waste by creating small, } \\
\text { customized production lots. } \\
\text {-Reduces the production cost. }\end{array}$ \\
\hline 8 & Simulation & $\begin{array}{l}\text { This involves reproducing } \\
\text { the physical world in virtual } \\
\text { models and allowing } \\
\text { operators to test and }\end{array}$ & $\begin{array}{l}\text { - Higher speed in prototyping that } \\
\text { increases production times; } \\
\text { - Reduced set-up costs, errors, and } \\
\text { machine downtimes. }\end{array}$ \\
\hline
\end{tabular}

Ratnasingam et al. (2020). "Industry 4.0, Malaysia" BioResources 15(3), 4866-4885. 4871 


\begin{tabular}{|c|c|c|c|}
\hline & & $\begin{array}{l}\text { optimize the settings to } \\
\text { obtain materials, productive } \\
\text { processes (discrete } \\
\text { elements), and products } \\
\text { (finished or distinct } \\
\text { elements). }\end{array}$ & \\
\hline 9 & $\begin{array}{l}\text { Horizontal and } \\
\text { Vertical } \\
\text { Integration }\end{array}$ & $\begin{array}{l}\text { The integration offered by } \\
\text { Industry } 4.0 \text { is } \\
\text { characterized by two } \\
\text { dimensions: } \\
\text { internal/horizontal and } \\
\text { external/vertical. A good } \\
\text { example is the material } \\
\text { requirement planning and } \\
\text { enterprise requirement } \\
\text { planning systems. }\end{array}$ & $\begin{array}{l}\text {-Reduced set-up costs, errors, and } \\
\text { machine downtime; } \\
\text {-Superior product quality due to } \\
\text { better connections in the incoming } \\
\text { and out-going supply chains; } \\
\text {-Higher production capacity and } \\
\text { increased productivity. }\end{array}$ \\
\hline 10 & $\begin{array}{l}\text { Other enabling } \\
\text { technologies }\end{array}$ & $\begin{array}{c}\text { Technologies such as } \\
\text { sensors and artificial } \\
\text { intelligence to reduce } \\
\text { waste. }\end{array}$ & $\begin{array}{c}\text { - Superior product quality and less } \\
\text { production waste due to optimized } \\
\text { production. }\end{array}$ \\
\hline
\end{tabular}

A study by Bauer et al. (2016) suggests that the intensive communication required by Industry 4.0 projects, and therefore the introduction of new technologies, may be significantly affected by the difficulty of coordination across organizational units. A study from Koch et al. (2014) found that many companies have not done feasibility studies to support the need to invest in the data and systems architecture required for the introduction of Industry 4.0 applications. Although most companies recognize the likely impact of Industry 4.0, it has been found that small and medium enterprises (SMEs) are generally less well-prepared for the new technologies and expectations due to financial constraints (Smit et al. 2016). In contrast, larger companies have much greater opportunities to invest in new technologies, and therefore tend to apply more advanced manufacturing technologies than SMEs (Dangayach and Deshmukh 2005). In fact, it was also reported by Basl (2017) that many companies are not clear on the benefits of using Industry 4.0 technologies and are also reluctant to explore such technologies due to the resistance arising from organizational culture in transformation. This is particularly relevant to the furniture industry in Malaysia, which is predominated by SMEs with family-based management culture.

Unlike previous studies, this paper examines the driving and inhibiting factors to Industry 4.0, in relation to the furniture industry. As far as we are aware, no previous papers have considered this context, and the results were not based on the furniture industry's ecosystem, which is essential for understanding the phenomenon. Against this background, it is important to assess the awareness and readiness of the Malaysian furniture industry for Industry 4.0. Although a previous paper by Ratnasingam et al. (2019) has provided some preliminary insights into this topic, their findings were inconclusive and required further research. Therefore, the main objective of this study is to assess the awareness and readiness of the Malaysian furniture industry for Industry 4.0 and industry attitudes about the benefits and potential challenges it may bring. The results of this study, which is part of a broader survey, will influence the development and implementation of university-level

Ratnasingam et al. (2020). "Industry 4.0, Malaysia" BioResources 15(3), 4866-4885. 4872 
program on Industry 4.0 under the Erasmus+ program and also highlight the potential reception and support it receives from the industry.

\section{EXPERIMENTAL}

\section{Methodology}

The aim of qualitative research is to gather data through the perception of local actors, paying considerable attention and drawing on empathic understanding to isolate key themes (Agee 2009). Being part of a broader study to develop and implement an Industry 4.0 university-level curriculum, this survey served the preliminary purpose of benchmarking the industry's current status in terms of their awareness, readiness, and the perceived barriers to the adoption of Industry 4.0. After evaluating the methodology of several previous studies on Industry 4.0 by Adolph et al. (2014), Cimini et al. (2017), Bauer et al. (2016), and Müller and Voigt (2017), it was decided that a structured questionnaire would fulfill the objectives of this study better. It was the opinion of the team that personal interviews should be avoided so that respondents do not feel that they are under pressure to meet the expectations of the group, hence affecting their responses (Acocella 2012). The team also did not set up hypotheses about the survey or use any predefined answers in the survey questions, to avoid processing errors and bias. The research data were triangulated by checking company websites and annual reports to increase the reliability and validity of our research. Respondents were assured of anonymity and confidentiality, to reduce bias and increase the reliability of the results.

\section{Target respondents}

A questionnaire-based survey was sent to 2000 furniture manufacturers in Malaysia. The manufacturers sampled were representative of the full spectrum of furniture products produced by the various sized manufacturers in the country. The response rate from potential respondents, who were identified with the assistance of the Malaysian Furniture Council (MFC), was 39\%, or 780 respondents.

\section{Questionnaire-based survey}

To meet study objectives, the questionnaire was prepared after intensive discussions with industry experts, academics, analysts from trade bodies, and partners from the Erasmus+ Project University Consortium (EPUC) for MAKING 4.0 for the Malaysian Furniture and Wood Industry.

The first part of the questionnaire compiled data on the background of the respondent, such as position of the respondent in the factory, factory-size (i.e. large, medium or small sized company), number of workers employed (i.e. including information type of workers such as highly skilled, semi-skilled or unskilled), type of products, target market, and years in operation. The second part of the questionnaire required the respondents to indicate the extent to which they employed automated technologies and report their reasons for adopting automated technologies. The third part of the questionnaire required the respondents to identify their most preferred key enabling technologies of Industry 4.0. The fourth part of the questionnaire required the respondents

Ratnasingam et al. (2020). "Industry 4.0, Malaysia" BioResources 15(3), 4866-4885. 4873 
to rank the relative importance of 19 attributes of automated technologies and Industry 4.0, which included factors such as increased output, on-time delivery, reduced down-time, shortened manufacturing cycle-time, reduced unit cost, higher return-on-investment (ROI), reduced workforce size, higher productivity, consistent quality, product diversity, improved quality, smaller batch-size, standardized components, reduced waste, less pollutants, improved ergonomics, improved safety and health factors, improved worker welfare, and increased manufacturing standard. Participants rated these attributes on a fivepoint Likert scale, which ranged from 1 (strongly unimportant) to 5 (strongly important). The fifth part of the survey required the respondents to evaluate their readiness to adopt Industry 4.0 and identify the main challenges they would expect to face.

\section{Data Collection}

The questionnaire was pre-tested among 30 randomly selected furniture manufacturers in the Klang Valley area in Malaysia in December 2018. After obtaining the responses and comments from the respondents, the questionnaire was modified accordingly to ensure clarity and ease of implementation. After dispatching the questionnaires, a follow-up reminder was made through telephone to all the potential respondents. At the end of the fifth week, a total of 780 furniture manufacturers had returned their completed questionnaires in the self-addressed and stamped envelope provided.

\section{Data Analysis}

The data from the questionnaires were compiled and tabulated using Microsoft Excel (2010) software (Microsoft, Las Vegas, NV, USA) to facilitate analysis. The analysis of data was conducted with version 25 of the Statistical Package for the Social Sciences (SPSS) (New York City, NY, USA). The reasons for the adoption of automated technologies among furniture manufacturers and the preferred key enabling technologies of Industry 4.0 were analyzed. Factor analysis was then performed on the 19 beneficial attributes of adopting Industry 4.0, which were then simplified into several groups of driving factors that influenced attitudes toward the adoption of Industry 4.0 among furniture manufacturers (Landscheidt and Kans 2016).

\section{RESULTS AND DISCUSSION}

The results of this study are presented in five parts: (1) the characteristics of the respondents, (2) factors that encouraged the adoption of automation technologies in furniture manufacturing, (3) the most preferred key enabling technologies of Industry 4.0 with the most potential applications reported by participants, (4) factor analysis of the 19 beneficial attributes of adopting Industry 4.0 technologies in furniture manufacturing, and (5) the readiness of furniture manufacturers to adopt and embrace Industry 4.0.

\section{Characteristics of the Respondents}

The survey results show that $63 \%$ of the respondents were involved in the export market only, while the other $37 \%$ of the respondents were involved in both the export and

Ratnasingam et al. (2020). "Industry 4.0, Malaysia" BioResources 15(3), 4866-4885. 4874 
domestic markets. This was expected, as the Malaysian furniture industry is an exportoriented industry with an $80 \%$ export to production ratio (Ratnasingam et al. 2018). Further, as Malaysia is a relatively small country with a population of 33 million and an average furniture expenditure of USD 380 per household per year, the domestic furniture market is relatively small (DOSM 2019).

Figure 1 shows that $91 \%$ of the respondents were from small- and medium-sized (SMEs) companies, and only $9 \%$ were from large-sized furniture manufacturers. Companies with a turnover from RM 300,000 up to RM 15 million per annum, from RM 15 million but not exceeding RM 50 million, and with annual turnover exceeding RM 50 million, are classified as small, medium and large respectively. As reported by Ratnasingam et al. (2018), the SMEs, including micro-based companies, predominate the furniture industry in Malaysia due to the fact that furniture manufacturing is still regarded as a cottage-based industry with a low barrier to entry and a large number of single, familybased entrepreneurs. Nevertheless, as reported by Horváth and Zs. Szabó (2019), larger companies may be financially stronger to pay for the higher investments required for adopting automated technologies compared to the SMEs. Despite the industrial structure, the SMEs remain the backbone of the robust and rapidly growing furniture industry, offering both flexibility in volume production and product diversity (Kiel et al. 2017).

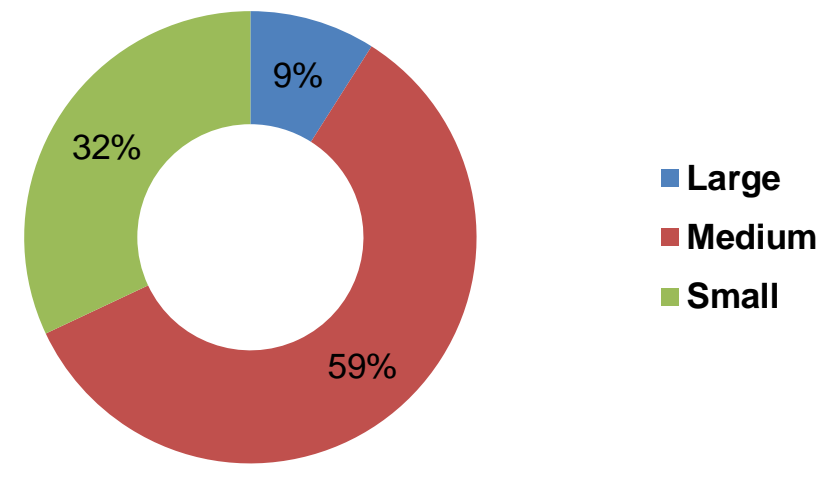

Fig. 1. Factory sizes of respondents

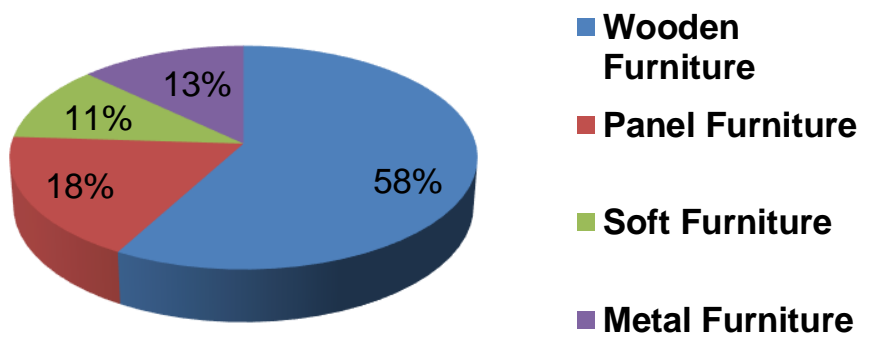

Fig. 2. The structure of the sample population regarding the type of furniture produced

Ratnasingam et al. (2020). "Industry 4.0, Malaysia" BioResources 15(3), 4866-4885. 4875 
Figure 2 shows that wooden furniture manufacturers constituted the largest proportion of respondents (58\%), followed by panel-based furniture (18\%), metal furniture (13\%), and soft/leather furniture (11\%). This trend was in line with the previously reported composition of the furniture industry in Malaysia, as wooden furniture accounts for the largest portion of the furniture produced in the country, making up almost $83 \%$ of all furniture produced (Ratnasingam et al. 2018).

\section{Reasons for Adopting Automated Technologies in Furniture Manufacturing}

Of the 780 respondents who participated in this survey, 57\%, or 444 respondents had invested up to RM 1.0 million over the last three years to acquire automated technologies. These respondents, in their opinion and perspective, reported that the main reasons in an order of importance, for acquiring these technologies were to: (1) improve productivity, (2) reduce workforce, (3) reduce cost, and (4) improve quality (Fig. 3). These findings were comparable to previous studies by Adolph et al. (2014), Paritala et al. (2017), Cimini et al. (2017) and Kiel et al. (2017), who reported that the acquisition of automation and high technologies were usually driven by the need for higher productivity and cost competitiveness. In fact, the results also goes parallel with the suggestion by Ratnasingam et al. (2019), who found that the growth of the furniture industry in Malaysia was due to incremental factor inputs, which also include the application of automated technologies. In fact, this revelation is also the basis on which the government introduced the Industry 4.0 Master Plan in 2018 (MITI 2018), so as to encourage the manufacturing sector to further embark on higher technology application.

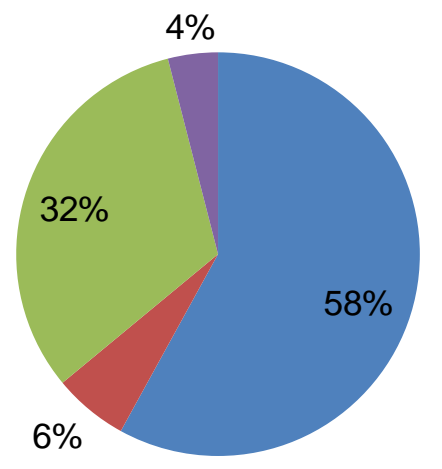

- Improve productivity

- Reduce cost

Reduce workforce

- Improve quality

Fig. 3. Reasons for adopting automated technologies

The results of the survey also revealed that panel-based furniture manufacturers reported the most use of automated technologies, followed by metal furniture, wooden furniture, and soft/leather furniture, in that respective order. This finding has serious implications for the furniture manufacturing industry, as it suggests that not all furniture industry segments can adopt similar levels of automated technologies. In addition, the available technologies appear better suited for furniture with standardized components of a great variety, which is a common feature in the panel-based and metal furniture industries (Ratnasingam et al. 2018). A similar point was also highlighted by Müller and Voigt (2017) who found that standardized components and products encourages the application of automated technologies.

Ratnasingam et al. (2020). "Industry 4.0, Malaysia" BioResources 15(3), 4866-4885. 4876 
The preference among panel-based furniture and metal furniture manufacturers to apply a higher degree of automated technologies in their manufacturing facility is driven by the need for consistent quality, lower unit cost, standardized components, and compliance to various standards (Bahrin et al. 2016). However, these findings conflict with other reports on the factors that encouraged the use of automated technologies in the furniture manufacturing industry. Ng and Kanagasundaram (2017) reported that automated technologies were the most appropriate means of manufacturing furniture in high-wage economies where technology application can off-set the high labor cost. In Japan, for instance, the application of automated technologies is more pervasive throughout the furniture manufacturing industry, even among small enterprises, due to the high cost of labor and strict environmental regulations (Bauer et al. 2016; Thoben et al. 2017). The high precision work culture of quality and consistency characteristics of the Japanese workforce necessitates the use of automated technologies, which often eliminate human errors that may impair overall product quality and fail to meet customer expectations. A similar finding was reported in a study by Ratnasingam et al. (2012) on the furniture industry in Singapore. In Singapore, the stringent labor laws encourage the application of automated technologies to comply with legal requirements and create a more effective working environment (Ratnasingam et al. 2012).

Nevertheless, Ratnasingam et al. (2018) found that the prevailing low-wage economy, typical of the furniture industry in other parts of Asia, serves as a strong deterrent to adopting automated technologies. Further, the lack of enforcement of the existing environmental regulations indirectly contributes to the poor state of workers' welfare, health, and safety (Koch et al. 2014, Ratnasingam et al. 2019). However, other studies have reported that the benefits of applying automated technologies in furniture manufacturing outweigh the high initial cost (Erol et al. 2016), and the delay on returns from such investments can be shortened significantly by the increased productivity offered by automated technologies (Bahrin et al. 2016; Wang et al. 2017). Although, the prevailing low-wage economy in the Malaysian furniture industry may impede the adoption of automated and Industry 4.0 technologies on a wider scale, this may change when the benefits to be derived from such technologies are realized by the manufacturers (Kiel et al. 2017).

\section{Most Preferred Key Enabling Technologies of Industry 4.0 Among Furniture Manufacturers}

Figure 4 contains the potential technologies of Industry 4.0 in the order of reported importance to furniture manufacturers. Advanced manufacturing technologies, including low cost automation and robotics, ranked the highest and were followed by other enabling technologies, including CAD-CAM, horizontal and vertical integrated manufacturing, such as MRP, computer-aided design (CAD), cyber security, and simulation. The preferred enabling technologies of Industry 4.0 were skewed towards technologies that could be easily adopted without much investment in hardware or human capital. This result was also in line with the findings of previous studies by Adolph et al. (2014), Ratnasingam (2015), and Smit et al. (2016), who found that the lack of knowledgeable and skilled workers appears to be a big threat to the full utilization of such technologies in the manufacturing sector. It is apparent that in the Malaysian furniture manufacturing industry, awareness of

Ratnasingam et al. (2020). "Industry 4.0, Malaysia" BioResources 15(3), 4866-4885. 4877 
the benefits of Industry 4.0 and its enabling technologies is low, and much education and promotion would be required to realize the objective of achieving higher productivity and value-addition from the application of such technologies. Until then, there is overwhelming evidence that the labor-intensive nature of the industry will remain the norm rather than the exception, as noted by Ratnasingam et al. (2018).

The results of the analysis of the 29 beneficial attributes of automated technologies that encouraged their use among furniture manufacturers were then evaluated. Table 2 presents the mean ranking of the effects automated technologies had on furniture manufacturing. Lower unit cost, higher output, consistent quality, standardized components, and higher productivity encouraged furniture manufacturers to adopt automated technologies in their factories. However, the high investment cost, lack of skilled workers, lack of incentives, lack of production-networking data, and low workers' wages were the main factors that deterred furniture manufacturers from employing automated technologies on a wider scale.

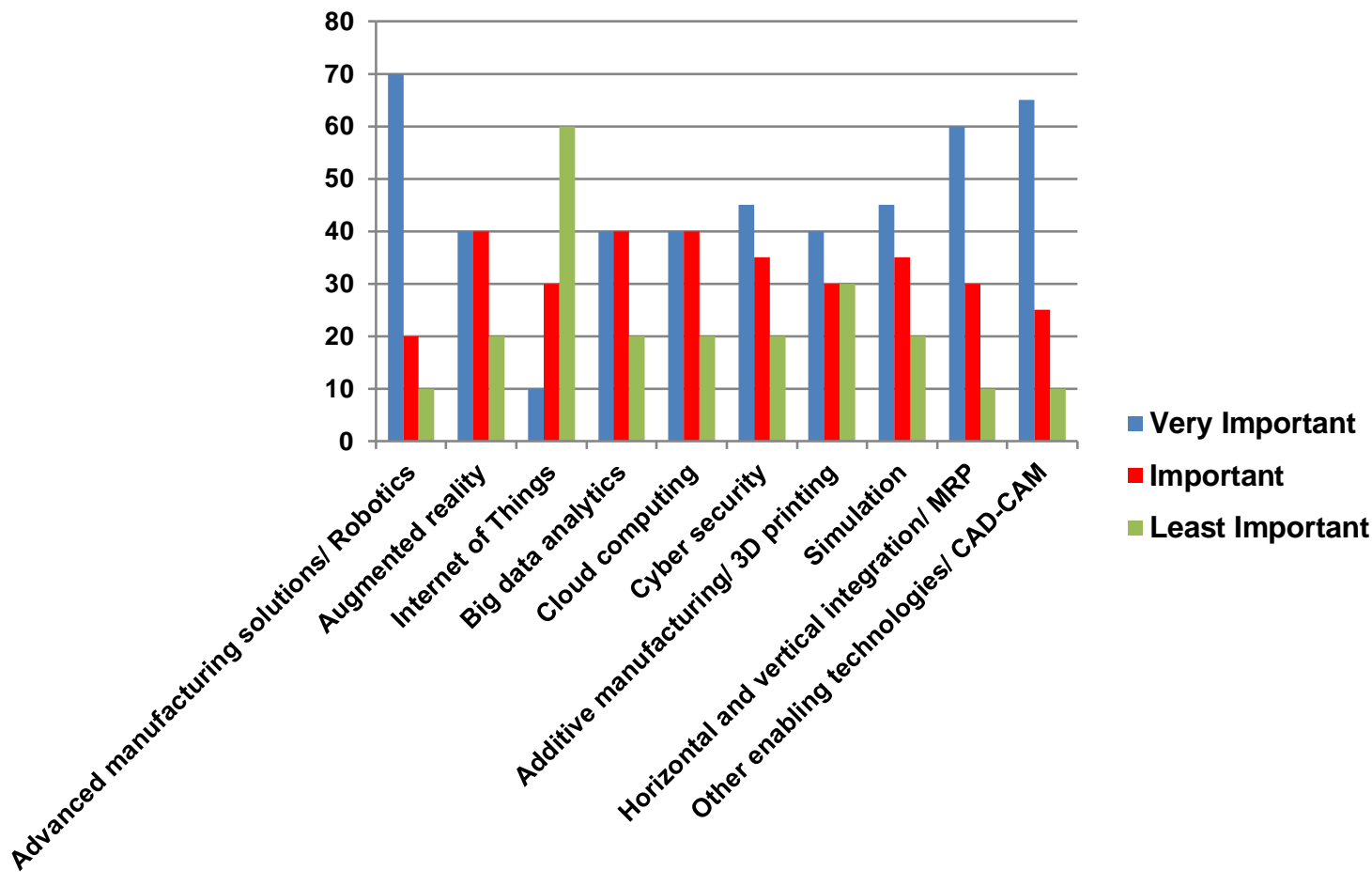

Technologies of Industry 4.0

Fig. 4. Enabling technologies of Industry 4.0 preferred among respondents

\section{Factor Analysis of Beneficial Attributes That Affected the Use of Automated Technologies in Furniture Manufacturing}

For factor analysis, all the variables in the study were assumed to be somewhat correlated, and the strength of the correlation among the variables was evaluated by the Kaiser-Meyer-Olkin method (Ho 2006). When this analysis was conducted, a weak correlation of 0.329 between the variables was found. However, the Bartlett's test of sphericity on the correlation matrix gave a value of 90.01 with a significance level of less

Ratnasingam et al. (2020). "Industry 4.0, Malaysia" BioResources 15(3), 4866-4885. 4878 
than 0.001. This showed significant correlations among some of the variables in the study, which indicated that factor analysis could be used for further analysis in this study.

Subsequently, the factor analysis grouped the 19 variables into five groups of attributes as follows: (1) production capacity, (2) cost, (3) work force, (4) product characteristics, and (5) work environment. Instead of describing the individual beneficial attributes of using automated technologies in furniture manufacturing, the factor analysis technique allowed consolidation of the many variables into five distinct groups, as shown in Table 2.

Table 2. Five Factor Solutions from the Factor Analysis of Attributes of Automated Technologies in Furniture Manufacturing

\begin{tabular}{|c|c|c|c|c|c|c|}
\hline No. & Factors & Attributes & $\begin{array}{l}\text { Solid Wood } \\
\text { Furniture }\end{array}$ & $\begin{array}{l}\text { Panel- } \\
\text { based } \\
\text { Furniture }\end{array}$ & $\begin{array}{c}\text { Soft } \\
\text { Furniture }\end{array}$ & $\begin{array}{c}\text { Metal } \\
\text { Furniture }\end{array}$ \\
\hline 1 & \multirow{4}{*}{$\begin{array}{l}\text { Production } \\
\text { Capacity }\end{array}$} & Increased Output & 3.8 & 4.4 & 2.9 & 4.1 \\
\hline 2 & & On-time Delivery & 3.8 & 3.8 & 3.3 & 3.1 \\
\hline 3 & & Reduced Down-time & 3.7 & 4.0 & 3.1 & 4.0 \\
\hline 4 & & $\begin{array}{c}\text { Shorter } \\
\text { Manufacturing } \\
\text { Cycle-time }\end{array}$ & 3.6 & 3.9 & 3.4 & 3.8 \\
\hline 5 & \multirow[b]{2}{*}{ Cost } & Reduced Unit Cost & 3.8 & 4.4 & 3.3 & 4.1 \\
\hline 6 & & $\begin{array}{l}\text { Higher Return on } \\
\text { Investment (ROI) }\end{array}$ & 3.1 & 3.6 & 3.0 & 3.5 \\
\hline 7 & \multirow[t]{2}{*}{ Work Force } & $\begin{array}{c}\text { Reduced Number of } \\
\text { Workers }\end{array}$ & 3.9 & 4.4 & 3.1 & 4.2 \\
\hline 8 & & Higher Productivity & 3.9 & 4.4 & 3.5 & 4.1 \\
\hline 9 & \multirow{5}{*}{$\begin{array}{l}\text { Product } \\
\text { Attributes }\end{array}$} & Consistent Quality & 4.0 & 4.3 & 2.9 & 4.3 \\
\hline 10 & & Product Diversity & 3.9 & 4.1 & 2.8 & 4.0 \\
\hline 11 & & Improved Quality & 3.8 & 3.5 & 2.9 & 3.6 \\
\hline 12 & & Smaller Batch Size & 3.4 & 4.0 & 3.5 & 4.0 \\
\hline 13 & & $\begin{array}{l}\text { Standardized } \\
\text { Components }\end{array}$ & 3.3 & 4.4 & 3.1 & 4.3 \\
\hline 14 & \multirow{6}{*}{$\begin{array}{c}\text { Work } \\
\text { Environment }\end{array}$} & Reduced Waste & 2.9 & 3.1 & 3.1 & 3.6 \\
\hline 15 & & Less Pollutants & 2.6 & 3.0 & 2.9 & 3.1 \\
\hline 16 & & $\begin{array}{l}\text { Improved } \\
\text { Ergonomics }\end{array}$ & 2.9 & 2.7 & 2.9 & 3.3 \\
\hline 17 & & $\begin{array}{l}\text { Improved Safety and } \\
\text { Health Conditions }\end{array}$ & 3.1 & 3.3 & 3.0 & 3.6 \\
\hline 18 & & $\begin{array}{c}\text { Improved Workers } \\
\text { Welfare }\end{array}$ & 2.8 & 3.1 & 3.0 & 3.8 \\
\hline 19 & & $\begin{array}{l}\text { Higher } \\
\text { Manufacturing } \\
\text { Standards }\end{array}$ & 3.8 & 3.9 & 3.1 & 4.1 \\
\hline
\end{tabular}

The factor analysis revealed that five factors influenced the furniture manufacturers' decision to apply automated technologies. In Table 2, the value of 4.0 is taken as the threshold value to show strong influence. Hence, all values above 4.0 are in bold to reflect its strong influence on the overall importance of the group, and the more such factors are present in the group, the higher is the overall importance of the group (Ho 2006).

Ratnasingam et al. (2020). "Industry 4.0, Malaysia" BioResources 15(3), 4866-4885. 4879 
The variance of factor 1 , factor 2 , factor 3 , factor 4 , and factor 5 accounted for $26.5 \%, 10.3 \%, 17.9 \%, 22.6 \%$, and $4.7 \%$, respectively, of the total variance observed among the variables. These results suggest that furniture manufacturers adopted automated technologies to improve their production capacity, enhance product characteristics, reduce workforce size, and minimize cost. Work environment did not have a strong influence on the decision-making process of furniture manufacturers to adopt automated technologies. This result was in line with those of previous studies by Li et al. (2019), Müller (2019), and Fareri et al. (2020), who found that production capacity, reducing workforce size, and cost were the primary motivation for manufacturers to adopt automated technologies. However, in an earlier report, Ratnasingam et al. (2018) argued that the Woodworking Machinery Suppliers Association (WMSA) of Malaysia regards the furniture industry as being production-oriented and highly cost-sensitive. Therefore, as elucidated by Ratnasingam et al. (2019), to achieve greater adoption of automated technologies in Malaysia's furniture industry, incentives and improved workforce training to cope with technologies of Industry 4.0 must be provided, with an implementation of a stringent policy to reduce workforce dependency (Ratnasingam et al. 2018).

\title{
The Level of Readiness among Furniture Manufacturers to Adopt and Embrace Industry 4.0
}

The results showed that the level of readiness to adopt Industry 4.0 among furniture manufacturers is relatively low at this point in time. Only $6 \%$ of the respondents were ready for the adoption of a high degree of automated technology, such as Industry 4.0. As expected, all the respondents who were more receptive and prepared to adopt a high degree of automated technology were from the wood-based panel and metal furniture manufacturing sector. The remaining $94 \%$ of the respondents were not ready to adopt Industry 4.0 and were mainly deterred by the high initial investment involved and a lack of networking infrastructure and data management capacity in their manufacturing facilities (Fig. 5).

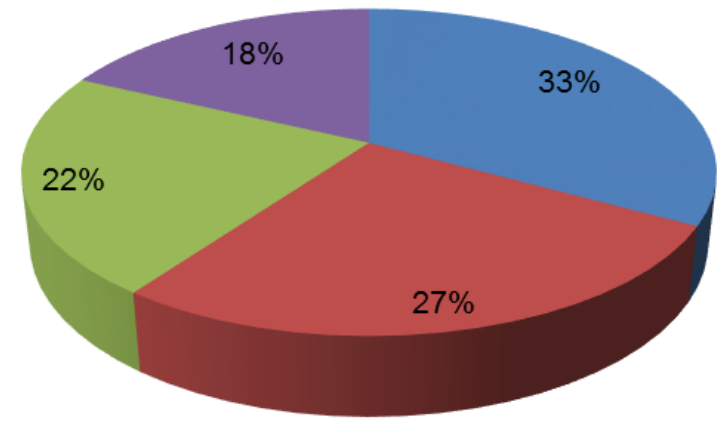

\author{
- High Investment Cost \\ - Lack of ICT Networking \\ Poor Data Management and \\ Analytics \\ - Insufficient Knowledgeable \\ Workers
}

Fig. 5. Deterrents to adopting Industry 4.0

These deterrent factors were listed based on their opinions and perspective of the industry, but were found to be in line with previous studies by Bauer et al. (2019), Horvat et al. (2018), and Müller (2019), suggesting that cost implications are high on the decision-

Ratnasingam et al. (2020). "Industry 4.0, Malaysia" BioResources 15(3), 4866-4885. 4880 
making hierarchy among SMEs, who predominate the furniture sector. Nevertheless, it must be recognized that without the availability of knowledgeable and skilled local workforce, the journey of embarking Industry 4.0 technologies may be slow and challenging for Malaysian furniture manufacturers.

In the final analysis, however, as long as the low-cost foreign contract workers are available, manufacturers of furniture in the country may continue to shun high technologies, while believing that these low-cost workers can offset the perceived benefits offered by the costly technologies (Bahrin et al. 2016).

\section{Implications of the Study}

The results of this study have far-reaching implications on the adoption and implementation of automated and industry 4.0 technologies among furniture manufacturers in the country. It appears that such technologies can be more readily adopted by wood-based panel and metal furniture manufacturers, who are akin to producing standardized products in large volumes, rather than the solid-wood and leather furniture manufacturers. Unlike their European counterparts in the furniture industry, Malaysian furniture manufacturers are still highly cost-sensitive, and the sales of their products are often driven by price points rather than productivity or value-addition (Ratnasingam et al. 2018). As highlighted by the study, one of the major barriers to the adoption of Industry 4.0 technologies in the furniture industry is the lack of knowledgeable and skilled workers to handle such technologies. In this context, the proposed Erasmus MAKING 4.0 university-level education program is both timely and desirable. However, the proposed education curriculum on Industry 4.0 should be broad-based rather than focusing exclusively on the furniture and wood-based industry to attract more students from different academic backgrounds and ensure its relevance to the country's needs. This is owing to the fact that generally interest among young people to pursue a degree in furniture and wood-related field is on the decline in the country, and therefore, a further degree focused on this field may not be widely acceptable either at this point of time. Inevitably, a generalized Industry 4.0 university-level education may be more amenable and attractive to both potential students as well as industry personnel. Further, based on higher the readiness of the wood-based panel and metal furniture manufacturers to Industry 4.0, it is recommended that the government provides further support to ensure greater uptake of such technologies, which in turn will increase the overall awareness of the benefits to be derived from such technologies to the larger furniture and wood-based industry. Such increased adoption is also highly desirable to boost industrial productivity, while at the same time, reducing the dependence on foreign contract workers. Finally, this study should convince policy makers that increasing awareness of the benefits of Industry 4.0 is equally important to providing the necessary incentives to facilitate a wider adoption of Industry 4.0 in the furniture and wood industry in Malaysia.

Ratnasingam et al. (2020). "Industry 4.0, Malaysia" BioResources 15(3), 4866-4885. 4881 


\section{CONCLUSIONS}

1. Generally, the wood-based panel and metal furniture manufacturers were more receptive to adopting automation and embracing the technologies of Industry 4.0, compared to the solid-wood and soft/leather furniture manufacturers.

2. Advanced manufacturing technologies, such as CAD-CAM, MRP, cyber-security, and simulation, were the most preferred enabling technologies of Industry 4.0.

3. The factor analysis revealed that the most beneficial attributes of adopting Industry 4.0 technologies (in order of declining importance) were increasing production capacity, improving product diversity, reducing workforce, and reducing production cost.

4. Improvement in the work environment did not have a strong influence on respondents' decisions to embrace Industry 4.0 technologies.

5. The lack of knowledgeable and skilled workers was one of the perceived barriers that prevented manufacturers from adopting the technologies of Industry 4.0. Therefore, the proposed Erasmus+ program on Industry 4.0 is both timely and relevant, and may offer the solution to train such workers.

\section{ACKNOWLEDGEMENTS}

The authors thank the Malaysian Furniture Council (MFC) and the Erasmus MAKING 4.0 program (Project No. 598783-EPP-1-2018-1-ES-EPPKA2-CBHE-JP) members for their expert support and assistance in implementing this study. The financial assistance extended through the Putra-Grant No. 9649900 from Universiti Putra Malaysia to cover the field survey cost is also acknowledged.

\section{DISCLAIMER}

The European Commission's support for the production of this publication does not constitute an endorsement of the contents, which reflect the views only of the authors, and the Commission cannot be held responsible for any use that may be made of the information contained therein.

\section{REFERENCES CITED}

Academy of Sciences Malaysia (ASM) (2015). Mega-Science Outlook Report: Furniture Manufacturing, Kuala Lumpur, Malaysia.

Acocella, I. (2012). "The focus groups in social research: advantages and disadvantages," Quality \& Quantity 46(4), 1125-1136.

Adolph, S., Tisch, M., and Metternich, J. (2014). "Challenges and approaches to competency development for future production," Journal of International Scientific Publications-Educational Alternatives 12(1), 1001-1010.

Ratnasingam et al. (2020). "Industry 4.0, Malaysia" BioResources 15(3), 4866-4885. 4882 
Agee, J. (2009). "Developing qualitative research questions: A reflective process," International Journal of Qualitative Studies in Education 22(4), 431-447. DOI: 10.1080/09518390902736512

Anderl, R., Haag, S., Schützer, K., and Zancul, E. (2018). "Digital twin technology - An approach for Industrie 4.0 vertical and horizontal lifecycle integration," IT Information Technology 60(3), 125-132. DOI: 10.1515/itit-2017-0038

Arnold, C., Kiel, D., and Voigt, K. I. (2016). "How Industry 4.0 changes business models in different manufacturing industries," in: XXVII ISPIM Innovation Conference Proceedings, Porto, Portugal, pp. 18-21.

Bahrin, M. A. K., Othman, M. F., Azli, N. H. N., and Talib, M. F. (2016). "Industry 4.0: A review on industrial automation and robotic," Jurnal Teknologi 78(6-13). DOI: $10.11113 /$ jt.v78.9285

Basl, J. (2017). "Pilot study of readiness of Czech companies to implement the principles of Industry 4.0," Management and Production Engineering Review 8, 3-8.

Bauer, H., Baur, C., Mohr, D., Tschiesner, A., Weskamp, T., Alicke, K., and Wee, D. (2016). Industry 4.0 after the initial hype - Where manufacturers are finding value and how they can best capture it. McKinsey Digital.

Bauer, W., Schuler, S., Hornung, T., and Decker, J. (2019). "Development of a procedure model for human-centered industry 4.0 projects," Procedia Manufacturing 39, 877885. DOI: 10.1016/j.promfg.2020.01.402.

Büchi, G., Cugno, M., and Castagnoli, R. (2020). "Smart factory performance and Industry 4.0," Technological Forecasting and Social Change 150, 119-129. DOI: 10.1016/j.techfore.2019.119790

Centre for Industrial Studies (CSIL) (2019). The Global Furniture Outlook, CSIL Publication, Milan, Italy.

Cimini, C., Pinto, R., Pezzotta, G., and Gaiardelli, P. (2017). "The transition towards industry 4.0: business opportunities and expected impacts for suppliers and manufacturers," In: IFIP International Conference on Advances in Production Management Systems, Springer, Cham., pp. 119-126.

Dangayach, G. S., and Deshmukh, S. G. (2005). "Advanced manufacturing technology implementation," Journal of Manufacturing Technology Management 16, 483-496. DOI: $10.1108 / 17410380510600473$.

Department of Statistics Malaysia (2019). Household Expenditure Survey in Malaysia. DOSM, Putrajaya, Malaysia.

Erol, S., Jäger, A., Hold, P., Ott, K., and Sihn, W. (2016). “Tangible Industry 4.0: A scenario-based approach to learning for the future of production," Procedia CIRP 54(1), 13-18. DOI: 10.1016/j.procir.2016.03.162.

Fareri, S., Fantoni, G., Chiarello, F., Coli, E., and Binda, A. (2020). "Estimating Industry 4.0 impact on job profiles and skills using text mining," Computers in Industry 118, 103222. ISSN 0166-3615. DOI: 10.1016/j.compind.2020.103222.

Ghobakhloo, M. (2018). "The future of manufacturing industry: A strategic roadmap toward Industry 4.0," Journal of Manufacturing Technology Management 29, 910936.

Hecklau, F., Galeitzke, M., Flachs, S., and Kohl, H. (2016). "Holistic approach for human resource management in Industry 4.0," Procedia CIRP 54(1), 1-6. DOI:

Ratnasingam et al. (2020). "Industry 4.0, Malaysia" BioResources 15(3), 4866-4885. 4883 
10.1016/j.procir.2016.05.102.

Hermann, M., Pentek, T., and Otto, B. (2015). "Design principles for Industry 4.0 scenarios: A literature review," Technische Universität Dortmund, Dortmund.

Ho, R. (2006). Handbook of Univariate and Multivariate Data Analysis and Interpretation with SPSS, Taylor \& Francis Group, Boca Raton, FL, USA.

Horvat, D., Stahlecker, T., Zenker, A., Lerch, C., and Mladineo, M. (2018). "A conceptual approach to analysing manufacturing companies' profiles concerning Industry 4.0 in emerging economies," Procedia Manufacturing 17, 419-426. DOI: 10.1016/j.promfg.2018.10.065.

Horváth, D., and Szabó, R. Z. (2019). "Driving forces and barriers of Industry 4.0: Do multinational and small and medium-sized companies have equal opportunities?" Technological Forecasting and Social Change 146, 119-132. DOI: 10.1016/j.techfore.2019.05.021.

Kiel, D., Müller, J. M., Arnold, C., and Voigt, K. I. (2017). "Sustainable industrial value creation: Benefits and challenges of Industry 4.0," International Journal of Innovation Management 21(8), Article ID1740015. DOI: 10.1142/S1363919617400151

Koch, V., Kuge, S., Geissbauer, R., and Schrauf, S. (2014). "Industry 4.0: Opportunities and challenges of the industrial internet," Strategy \& $P w C$.

Landscheidt, S., and Kans, M. (2016). "Automation practices in wood product industries: Lessons learned, current practices and future perspectives," in: The $7^{\text {th }}$ Swedish Production Symposium SPS, 25-27 October, 2016, Lund, Sweden. Lund University.

Li, D., Landström, A., Fast-Berglund, Å., and Almström, P. (2019). "Human-centred dissemination of data, information and knowledge in industry 4.0," Procedia CIRP 84, 380-386. ISSN 2212 8271. DOI: 10.1016/j.procir.2019.04.261.

Malaysian Furniture Council (MFC) (2017). State of Automation in the Furniture Industry in the Central Region of Peninsular Malaysia (Report No. 4/17), Malaysian Furniture Council, Kuala Lumpur, Malaysia.

Malaysian Timber Industry Board (MTIB) (2019). Assessment of the Malaysian WoodBased Industry, Malaysian Timber Industry Board, Kuala Lumpur, Malaysia.

Ministry of International Trade and Industry (MITI) (2018). Industry 4WRD: National Policy on Industry 4.0, Ministry of International Trade and Industry, Kuala Lumpur, Malaysia.

Müller, J. M. (2019). "Assessing the barriers to Industry 4.0 implementation from a workers' perspective," IFAC-PapersOnLine 52(13), 2189-2194. DOI: 10.1016/j.ifacol.2019.11.530.

Müller, J., and Voigt, K. I. (2017). "Industry 4.0-Integration strategies for small and medium-sized enterprises," in: Proceedings of the $26^{\text {th }}$ International Association for Management of Technology (IAMOT) Conference, Vienna, Austria, pp. 14-18.

Ng, B. K. (2011). Technological Innovation Patterns among Malaysia's Small and Medium-Sized Wooden Furniture Manufacturers: A Sectoral Innovation Systems Perspective, Ph.D. Dissertation, University of Malaya, Kuala Lumpur, Malaysia.

$\mathrm{Ng}$, B. K., and Kanagasundaram, T. (2017). "Sectoral innovation systems in low-tech manufacturing: Types, sources, drivers and barriers of innovation in Malaysia's wooden furniture industry," Institutions and Economies 3(3), 549-574.

Ratnasingam et al. (2020). "Industry 4.0, Malaysia" BioResources 15(3), 4866-4885. 4884 
Paritala, P. K., Manchikatla, S., and Yarlagadda, P. K. (2017). "Digital manufacturingapplications past, current, and future trends," Procedia Engineering 174, 982-991.

Ratnasingam, J. (2015). The Malaysian Furniture Industry: Unravelling its Growth and Challenges to Innovation, Universiti Putra Malaysia Press, Serdang, Malaysia.

Ratnasingam, J. (2019). Developing Knowledge Workers for the Advent of Industry 4.0 in the ASEAN Furniture Industry (IFRG Report No. 6), IFRG, Singapore.

Ratnasingam, J., Ab Latib, H., Yi, L. Y., Liat, L. C., and Khoo, A. (2019). "Extent of automation and the readiness for Industry 4.0 among Malaysian furniture manufacturers," BioResources 14(3), 7095-7110. DOI: 10.15376/biores.14.3.70957110

Ratnasingam, J., Chin, K. A., Latib, H. A., Subramaniam, H., and Khoo, A. (2018). "Innovation in the Malaysian furniture industry: Drivers and challenges," BioResources 13(3), 5254-5270. DOI: 10.15376/biores.13.3.5254-5270

Ratnasingam, J., Ioras, F., and Abrudan, I. V. (2012). "An evaluation of occupational accidents in the wooden furniture industry - A regional study in South East Asia," Safety Science 50(5), 1190-1195.

Roblek, V., Meško, M., and Krapež, A. (2016). “A complex view of industry 4.0," Sage Open 6(2), 2158244016653987.

Smit, J., Kreutzer, S., Moeller, C., and Carlberg, M. (2016). Industry 4.0, Study for the ITRE Committee, Policy Department A: Economic and Scientific Policy. Eur Parliament, Brussels.

Thoben, K. D., Wiesner, S., and Wuest, T. (2017). "Industry 4.0 and Smart Manufacturing: A review of research issues and application examples," International Journal of Automation Technology 11(1), 4-16. DOI: 10.20965/ijat.2017.p0004

Valenduc, G., and Vendramin, P. (2016). Work in the Digital Economy: Sorting the Old from the New, Vol. 3, European Trade Union Institute, Brussels.

Wang, L., He, J., and Xu, S. (2017). "The application of Industry 4.0 in customized furniture manufacturing industry," in: $13^{\text {th }}$ Global Congress on Manufacturing and Management (GCMM 2016), Zhengzhou, China, pp. 30-32. DOI: $10.1051 /$ matecconf/201710003022

Zhong, R. Y., Xu, X., Klotz, E., and Newman, S. T. (2017). "Intelligent manufacturing in the context of industry 4.0: a review," Engineering 3(5), 616-630.

Article submitted: February 7, 2020; Peer review completed: April 29, 2020;

Revised version received and accepted: May 4, 2020; Published: May 8, 2020.

DOI: $10.15376 /$ biores. 15.3.4866-4885 